\title{
Movimiento por la Paz con Justicia y Dignidad: construir paz en la guerra de México
}

\author{
Pietro Ameglio Patella \\ Universidad Nacional Autónoma de México (UNAM), Servicio Paz y Justicia \\ (SERPAJ)-México. \\ Email: serpajc@laneta.apc.org
}

\begin{abstract}
Resumen: En este artículo se reflexiona sobre las formas de lucha noviolentas ejercidas por el Movimiento por la Paz con Justicia y Dignidad (MPJD), como fuerza moral, en el contexto de guerra de México y de las diferentes fases de resistencia civil que ha ido ejerciendo la sociedad.

Se analizan las etapas de las estrategias y tácticas noviolentas que realizó el MPJD de 2011 a 2013, en donde los familiares de víctimas comenzaron a dar su testimonio de dolor, indignación y su determinación de luchar para encontrar a sus desaparecidos; hacer justicia a sus muertos y "parar la guerra" en las plazas de México y ante los medios nacionales e internacionales. Se logró convocar por momentos a una parte importante de la reserva moral nacional, ejerciendo presión moral y material hacia el poder político, señalado por los familiares como directamente responsable de la muerte o desaparición, en contubernio con el delito organizado.
\end{abstract}

Palabras clave: Movimiento por la paz, estrategia y lucha noviolenta, reserva moral, guerra, víctimas.

\section{Movement for Peace with Justice and Dignity: to build peace in the war of Mexico}

\begin{abstract}
This article discusses about the forms of nonviolent struggle exercised by the Movement for Peace with Justice and Dignity (MPJD), as a moral force, in the context of war in Mexico, and on the different phases of civil resistance that has been exercising society.

The stages of nonviolent strategies and tactics developed by the MPJD in the plazas of Mexico and before national and international media, from 2011 to 2013, where the families of victims began to give their testimony of pain, indignation, and their determination to fight in order to find their "missing" ones, do justice to their dead and "Stop the War", are analyzed here. In these they managed to summon an important part of the national "moral reserve", exercising "moral and material pressure" towards political power, pointed out by the families as directly responsible for the death or disappearance, in collusion with organized crime.
\end{abstract}

Keywords: Movement for Peace, nonviolent strategy and struggle, Moral Reserve, War- Victims. 


\title{
Movimento pe la Paz com Justiça e Dignidade: para construir a paz na guerra do México
}

\begin{abstract}
Resumo: Este artigo reflete sobre as formas de luta não-violenta realizadas pelo Movimento PE la Paz com Justiça e Dignidade (MPJD), como uma força moral no contexto da guerra no México e as diferentes fases de resistência civil que tem sido exercidas PE La sociedade.

Analisam-se as etapas das estratégiase táticas não-violentas que realizou o MPJD de 2011 a 2013, onde os parentes das vítimas começaram a prestar testemunho de dor, raiva e sua determinação de lutar para encontrar os seus desaparecidos; fazer justiça a seus mortos e "parar a guerra” nas praças do México e diante a mídia nacional e internacional. Foi possível reunir às veze suma parte importante da reserva moral nacional, exercendo pressão moral e material para o poder político, identificado por parentes como diretamente responsável??PE La morte ou desaparecimento, em conluio com o crime organizado.
\end{abstract}

Palavras-chave: Movimento PE la paz, estratégia e luta não-violenta, reserva moral, guerra, vítimas.

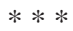

\section{El estado del poder en México es la guerra}

Partir de la construcción de un buen "principio de realidad"1 es la mejor arma -en cualquier sentido- para iniciar una lucha y/o reflexión, por ello queremos caracterizar desde el inicio al orden social mexicano actual dentro de la conceptualización de "la guerra", algo ampliamente encubierto desde el poder y los medios, con una imagen muchas veces simplista acerca de "la violencia". Por eso nos parece fundamental empezar esta reflexión desde este principio de realidad, con el fin de comprender mejor el espacio social, en qué piso se insertan las luchas noviolentas en México de los familiares de víctimas y la sociedad civil solidaria del 2011 al 2013², en particular del Movimiento por la Paz con Justicia y Dignidad (MPJD), en una de las experiencias y movilizaciones de masas más grandes que han existido en el país y en América Latina en los últimos años.

Así, para cualquier análisis, no se debe olvidar que México es un territorio atravesado por “acciones de guerra”(Marín 2007: 47) en todas sus partes, aunque no con la misma intensidad y forma en cada región. Esta guerra, en una muy breve descripción podemos decir que tiene al menos tres caracterizaciones centrales, en sus aspectos más violentos: es civil (toca en forma transversal a todos los sectores de la población en los enfrentamientos armados, en lo económico y lo social), es de "exterminio masivo" y de "exterminio selectivo" (Colectivo "Angela Esperanza” 2014). Estas formas de exterminio masivo alcanzan en los últimos años desde el 2007, según cifras de organizaciones no-gubernamentales, más de 102 mil muertos (Olivares 2015), 32 mil desaparecidos (Román 2016), ${ }^{3}$ según organizaciones de víctimas y cientos de miles de desplazados (Román 2015). Cifras que han sido comparadas -entre otros 
por Amnistía Internacional- con la guerra en Bosnia, Irak, Ruanda y las dictaduras sudamericanas en los setenta (Román 2015).

Hoy día sabemos también, sobre todo gracias a los numerosos movimientos de familiares de víctimas de esta guerra, en lo que fue también un gran logro del MPJD, que la inmensa mayoría de las víctimas no tenían ninguna relación con el delito organizado y eran miembros honrados de la sociedad civil, como cualquiera de nosotr@s, cuyas vidas fueron atravesadas por una coyuntura territorial y social de enorme inhumanidad. Las movilizaciones e investigaciones personales -valientes y heroicas- de los movimientos de víctimas y el MPJD, y denuncias públicas masivas lograron visibilizar la dignidad de sus familiares y la falsedad de la imagen oficial de que se trataba de "una guerra contra el narco", cuando en realidad se trata de una guerra intercapitalista trasnacional por el monopolio de una nueva mercancía ilegal, así como de otros al menos 23 delitos, por el control de los cuerpos y recursos materiales y naturales en los territorios del país (Equipo Bourbaki 2011). En esta guerra, como en todas, hay bandos, y en cada bando hay representantes del delito organizado, del aparato de poder estatal en todos sus niveles, de fuerzas con armas legales y no, de empresarios, y de porciones de la sociedad civil directa o indirectamente involucrada.

Finalmente, como parte de la caracterización de este proceso de guerra que nos atraviesa, el "exterminio selectivo", siempre presente en la historia mexicana, se ha incrementado últimamente en forma elevada, con un nivel de impunidad total existente. En el estado de Guerrero, por ejemplo, en los últimos tres meses del 2013 habían sido asesinados casi 20 líderes sociales en forma totalmente impune, y como parte de ese mismo proceso en ese estado el 26-27 de septiembre de 2014 -en una "acción genocida"- fueron desaparecidos brutalmente -hasta hoy-, por policías y delincuentes, con la complicidad y omisión de funcionarios públicos de todos los niveles de poder ${ }^{4}, 43$ estudiantes normalistas rurales de Ayotzinapa en Iguala. Se abrió así la interrogante: ¿el "exterminio selectivo", del que los estudiantes normalistas siempre han sido víctimas por su radicalismo justiciero de izquierda, podría convertirse en un "exterminio masivo" si se activan cierto tipo de decisiones genocidas?

\section{La reserva y la frontera moral en México}

¿Cómo ha enfrentado y resistido la sociedad civil mexicana en esta guerra? Una importante "arma noviolenta", y de cualquier otro tipo de lucha social de masas, es la llamada "reserva moral" (Ameglio 2013 y 2011). ${ }^{5}$ En la historia de la mayoría de los pueblos del mundo, en contados momentos de excepcional inhumanidad, se ha manifestado públicamente -de diferentes maneras- una porción muy importante de la sociedad exclamando un “ ¡Alto a la inhumanidad!”, una especie de delimitación de una "frontera moral” que -como conjunto social- no se está dispuesto a atravesar, una expresión de indignación moral y rebelión ética. En estas masas indignadas las personas tienen identidades muy diferentes, y hasta contradictorias, 
pero ante esa coyuntura tan violenta se unen por metas y valores superiores, incluso a veces para salvaguardar su propia existencia material. Estas acciones aparecen pocas veces en la historia, se realizan en excepcionales momentos de peligro de la vida y la moral de una nación y sus individuos, pero cuando lo hacen tienen un carácter decisivo en el proceso social que impugnan.

En las últimas décadas de México, hemos visto aparecer esta masiva reserva moral en la calle en especiales ocasiones: con el trabajo voluntario ante la ineficiencia gubernamental frente a los sismos del 85; en la multitudinaria concentración del zócalo que pidió el “Alto a la guerra” y el fin de los bombardeos gubernamentales a los zapatistas el 11 de enero del 94; en el repudio a la masacre de Acteal (22 de diciembre del 97); en las gigantescas marchas contra el desafuero de López Obrador y el fraude electoral del 2006; en las igualmente enormes marchas de Oaxaca por la destitución del gobernador Ulises Ruiz... Así, a partir de re-construir esta autonomía inicial de parte de la sociedad frente al gobierno y la co-operación (individual y colectiva) (Piaget 1985), se pudo avanzar en un proceso hacia la realización de un principio central de la noviolencia y la humanización de la especie: “debemos ser capaces de sensibilizarnos ante cualquier acto de inhumanidad y tratar de que la desobediencia debida sea la respuesta de todo nuestro pueblo: una moral de la autonomía se forja cuando se comprende, y se aprende, que hay que desobedecer toda orden de inhumanidad” (Marín 1995; 2007: 34). ${ }^{6}$

En esta etapa reciente de la historia de México, los hechos sociales más brutales de guerra, por desgracia, han sobreabundado: masacre de 49 niñ@s de la Guardería ABC en Hermosillo (Sonora) el 5 de junio de 2010; masacre de 16 jóvenes en Villas de Salvárcar (Cd. Juárez, Chihuahua) el 31 de enero de 2010; masacre de 72 migrantes en San Fernando (Tamaulipas) el 22 de agosto de 2010; masacre de 52 personas en el Casino Royale (Monterrey, Nuevo León) el 26 de agosto de 2011.Considero estos hechos que menciono brevemente como de "excepcional inhumanidad” por varias razones, por lo que constituyen una parte delimitante extrema de esa frontera moral de una sociedad que mencionábamos antes, y se trata, por tanto, del tipo de hechos que "no se pueden dejar pasar y normalizar" sin masivas expresiones públicas en la calle, de repudio ciudadano y exigencia de “¡Justicia Inmediata!”, continuando enseguida con otras acciones noviolentas de mayor intensidad. En ninguno de estos hechos, la reserva moral mexicana amplia salió con suficiente determinación, intensidad de acción y cantidad de gente a la calle para expresar su exigencia de “¡Ya Basta!”, o sea, que hasta que no haya verdad, justicia y reparación "No nos vamos a mover de aquí”: esta es la “Firmeza Permanente” (Barbé 1977) de la noviolencia. Se dejó así avanzar más en su grado de inhumanidad la frontera moral nacional, y las consecuencias -en cuanto al incremento de la impunidad y la espiral de guerra- de ese "silencio social masivo" o de la falta de determinación de lucha noviolenta proporcional a tan alta violencia, se empezaron a padecer cada vez más hasta hoy. 
Por otro lado, la reserva moral no es sólo una cuestión de cantidad de gente y masas, pues existen cuerpos que concentran -por su identidad social (obispos o jerarquías de todas las iglesias, rectores, intelectuales y artistas, líderes políticos, campesinos-obreros...)- más "fuerza social” que otros, y esos son precisamente los que también pensamos han estado (casi) ausentes -con sus cuerpos por delante en acciones noviolentas más radicales- en manifestaciones públicas claras ante tamañas inhumanidades, para convocar a la sociedad civil a acciones directas, para "protegerla" y hacer una crítica y presión fuertes hacia el poder y las fuerzas de la violencia. Al hablar de acciones no nos referimos al plano declarativo-mediático, o de política y función institucional, sino a otros grados de acciones noviolentas que guardaran una relación de escala semejante a las de la violencia ${ }^{7}$. Ya no basta con ser críticos del orden social o de ciertas autoridades en foros, homilías o mesas redondas, o con hacer denuncias mediáticas o jurídicas, sino que es necesario comprometerse con el propio cuerpo -"meter el cuerpo con una temporalidad indeterminada"- en ayudar a cambiar el proceso constituyente de la violencia, desprocesar la cultura inhumana y sus principales actores.

\section{Cuatro gritos masivos de indignación nacional}

A su vez, desde 2011 se han vivido en México cuatro Gritos Masivos de Indignación Moral que se prolongaron en su eco en procesos de lucha social, profundamente conectados con el Grito indígena maya zapatista del $1^{\circ}$ de enero de 1994 del “¡Ya Basta!”, que es realmente el inicio de esta nueva etapa de resistencia civil mexicana y mundial.

El Primer Grito empezó el 28 de marzo del 2011, con el "Estamos hasta la Madre” lanzado por el poeta Javier Sicilia, ante el brutal asesinato de su hijo Juan Francisco y otras seis personas en Cuernavaca (Morelos). Fue inmediatamente seguido por un número muy grande de víctimas individuales en todo México y de sociedad civil solidaria, quienes luego construyeron un gran movimiento nacional de víctimas que constituyó en mayo de ese año el MPJD. Con base en una serie inicial de grandes movilizaciones sociales en todo el país se logró: visibilizar el horror y la magnitud de la guerra en el país; dignificar a las víctimas en su identidad social e historia particular, organizarlas y consolarlas, convertirlas en sujetos sociales de derechos humanos, paz, verdad y justicia; romper la normalización de lo inhumano y el terror de este modelo de "paz armada”, demostrándolo como agravante de la violencia, como un gran negocio y que tiene como parte directa asociada al delito organizado a porciones del gobierno en todos sus niveles, a empresarios y a sectores de la sociedad civil; cuestionar de fondo el modelo económico capitalista neoliberal que nos imponen como gran reproductor de la pobreza y el desamparo en todos los sectores sociales, especialmente de los niños y jóvenes.

En mayo del 2012, el Segundo Grito dado por los jóvenes -también masivo pero relacionado más con la política, los medios de comunicación y 
la democracia- lo dio el movimiento “\#YoSoy132”, que aparte de ser un gran estallido con deseos de democracia, de participación de los jóvenes y de oponerse a la manipulación de un proceso electoral, fue también una forma noviolentade "Dar la Cara”, de enfrentar al poder, mirarlo a los ojos y decirle que "Estamos hasta la madre de su manipulación y Ya Basta de imponer presidentes y formas corruptas de hacer política”(Barbé 1977).

En febrero de 2013 se registró un Tercer Grito -más regional-, el de las autodefensas comunitarias michoacanas, víctimas comunitarias -sobre todo de clase media y pauperizadas- de esta guerra: el doctor José Manuel Mireles, líder histórico de este movimiento en Tepalcatepec (Michoacán), exclamaba que llega un momento en que hay que decir “¡Ya No!” (Gil-Olmos 2013). Esta afirmación llegó porque un sector de la sociedad rural-urbana aprendió con su propio dolor que en esta coyuntura mexicana por el camino de presionar noviolenta y simbólicamente a la autoridad, y esperar a que cambie y actúe para detener la guerra, no se había avanzado mucho, y ante el aumento brutal en el nivel de inhumanidad y agresión violenta a sus familias, decidieron asumir en forma directa -con mucha valentía, dignidad y autonomía del gobierno en todos sus niveles- su propia autodefensa comunitaria armada. Se dieron cuenta de que para vivir humanamente en su territorio debían instalar un poder paralelo, en cuanto a su propia seguridad

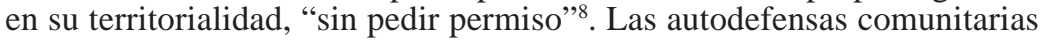
entendieron que en México no se trataba de un "Estado fallido", o de un Estado que hacía la "Guerra al narco" como proclamaba el gobierno, sino de un "Estado Delictivo" y profundamente involucrado en la guerra de bandas por controlar una mercancía ilegal, los territorios y los cuerpos (Equipo Bourbaki 2011). Esta determinación de asumir una "autodefensa armada" como último recurso para detener la "mano asesina" e impune del contubernio delito-gobierno, como una “determinación de fuerza moral”, desesperación y dignidad, nos abre abiertas muchas interrogantes acerca del estado de las cosas en que aún se encuentra la lucha noviolenta ${ }^{9}$ para enfrentar procesos de elevado ataque directo armado en medio de la total impunidad y aterrorizamiento social; es también un cuestionamiento acerca del real estadio actual de la especie humana frente a la violencia.

Finalmente, en septiembre del 2014, ante la acción genocida del gobierno y la delincuencia en Iguala contra 43 estudiantes normalistas rurales, grandes masas nacionales e internacionales volvieron a llenar las calles del país con el Cuarto Grito Nacional de Indignación Masiva bajo la consigna de "Fue el Estado". Incluso, parte de la sociedad elevó, en una indispensable búsqueda de mayor radicalidad y proporcionalidad de las acciones noviolentas respecto a las de la violencia, el nivel de las acciones directas hacia la no-cooperación (paros, dualidad de poder municipal...) y la desobediencia civil, pero por poco tiempo. Hoy día el Grito de "Fue el Estado" ya no es suficiente pues sirve, en parte, a mantener la impunidad, ya que es como decir que no fue nadie en particular y, en cambio, es fundamental dar nombres concretos de esa complicidad que existió, exigir verdad, justicia y reparación a las víctimas, y sobre todo que “Aparezcan los 43”. 


\section{Las formas noviolentas de lucha del MPJD}

Un actor determinante para tratar de "Parar la Guerra", y sus efectos directos e indirectos inhumanos, han sido los familiares de víctimas individuales, que pasaron de un gran dolor, encierro y terror a ser actores sociales públicos con gran valor y dignidad: son leones luchando como pueden por buscar la verdad, los cuerpos y la justicia. Otro efecto positivo de este proceso de construcción de defensores de derechos humanos y constructores de paz en que se han convertido hoy muchas de las víctimas en el país - y que fue desencadenado en parte por el MPJD- es que se multiplicaron y empoderaron las organizaciones de familiares de víctimas en todos los estados, y otras organizaciones ya existentes han crecido mucho en su lucha ejemplar, llegando en la actualidad a más de 50 .

Los pueblos y comunidades de víctimas colectivas, con su resistencia "civil y pacífica” contra el despojo de sus territorios, cultura y riquezas, han sido el otro actor fundamental de la resistencia civil noviolenta en el país, con una enorme radicalidad y valentía en sus acciones, a pesar del alto costo humano. Algunos de estos pueblos como Cherán, los wirrárikas, el Consejo de Pueblos de Morelos... se integraron desde el inicio al MPJD. (Ameglio 2012)

\section{Primera etapa: ofensiva estratégica noviolenta}

Pasemos ahora a explorar con un poco de mayor descripción y análisis el proceso de lucha social noviolenta del MPJD en sus primeros dos años. Podemos así señalar que la primera etapa de fuerte movilización inició con varias grandes marchas nacionales (paralelas en muchas ciudades) donde se comenzó a visibilizar la magnitud de las víctimas de la falsamente llamada por el presidente Felipe Calderón "Guerra al narco", la dignidad e identidad social de la mayoría de las víctimas que no estaban involucradas en el delito organizado como afirmaba la autoridad y la fuerza moral de ellas bajo el liderazgo humano y mediático de Javier Sicilia, la necesidad de organizarse entre las víctimas y denunciar al gobierno por no apoyarles, la urgencia de cambiar la política de paz armada y militarización de la seguridad pública. Posteriormente, se desarrolló una Caminata del Silencio ${ }^{10}$ (arma noviolenta material y moral) de víctimas y sociedad civil, durante cuatro días desde Cuernavaca al DF, que culminó con una multitudinaria marcha (8 de mayo de 2011) donde la población rompió su miedo y aterrorizamiento y salió masivamente a la calle. Por tres horas en el zócalo de la capital del país se escucharon setenta y dos testimonios de familiares de víctimas de todos los rincones de México y el anuncio de un Pacto Nacional Contra la Guerra y por la Paz. En el discurso de Javier Sicilia, quizá se planteó la acción del MPJD más radical y de consecuencias más reales para la justicia y el fin de la guerra: en medio de una gran fuerza social en la calle y de una gran capacidad de presión política, se pidió la "Renuncia de Genaro García Luna”, jefe de la Seguridad Pública nacional y fuertemente señalado por todos los 
sectores -incluso del gobierno de Estados Unidos- como directamente ligado al delito organizado. Era el momento de mayor "acumulación de fuerza moral y material" del movimiento, y de mayor "debilidad" del gobierno frente a él, por el gran apoyo de la sociedad y medios nacionales e internacionales; la acción apuntaba directo al corazón del contubernio delito-gobierno, origen y causa central de esta guerra. Al otro día, sin embargo, el movimiento corrigió y matizó esa demanda, que efectivamente entrañaba alto riesgo a las vidas de todos. De todos modos, ése fue un momento de gran importancia en esta lucha noviolenta pues, como diría Gandhi, se "desnudó la verdad" ante el país de esta guerra con su inmensa carga de dolor e impunidad; se tuvo también, en algo que resultó fundamental como arma noviolenta para presionar al poder, un gran eco en toda la prensa nacional e internacional.

Las semanas siguientes se dedicaron a la construcción de un movimiento social nacional (MPJD) centrado en las víctimas de la guerra; se comenzaron a tejer redes también con las "víctimas comunitarias" de esta guerra de exterminio y despojo, que eran los pueblos indios y campesinos; comenzó también a formalizarse un complejo y nada fácil proceso de organización y articulación entre individuos, grupos, ONGs, movimientos nacionales de muy diversas identidades, ideologías y experiencias de lucha unidos por el "Alto a la Guerra” y que "Aparezcan los desaparecidos"; empezó asimismo a construirse la Red Global para la Paz.

En paralelo, se fue también construyendo una gran movilización y "estado de agitación” a través de medio territorio nacional, de la capital hacia el norte (la zona más desolada y desprotegida contra el crimen organizado). La "Caravana del Consuelo" -del DF a Ciudad Juárez (2-10 junio)-, permitió visibilizar a la nación y el mundo los testimonios -sobre todo individuales- de víctimas, con lo que fue quedando en gran evidencia la enorme complicidad oficial en este proceso de guerra, y la ausencia de una política real de verdad y justicia. Otro objetivo, que concluyó con un resultado negativo (por muy diversas y complejas razones que involucran a todas las partes en conflicto), fue que la sociedad civil, en sus muchas identidades, firmara masivamente el 10 de junio -en forma por demás precipitada- un Pacto Nacional por la Paz, que tuvo un contenido muy amplio y con algunas demandas incluso hasta antagónicas entre sí, sin "principio de realidad" consensado, porque el texto se construyó apresuradamente a partir de unas mesas de trabajo que se tuvieron en la mañana del mismo día, lo que creó fracturas y enconos en la organización del naciente MPJD. Este hecho debilitó mucho el proceso organizativo posterior del movimiento y la desconfianza entre muchos actores, algo fundamental para la construcción de la estrategia noviolenta.

Dentro de la Caravana valdría la pena reflexionar acerca de una de las múltiples acciones que hubo, en esa experiencia que constituyó una forma de "interposición noviolenta de cuerpos en medio de un territorio en guerra”. El 6 de junio se realizó un acto nocturno muy emotivo de testimonios de víctimas en Monterrey, y ya se venía reflexionando colectivamente más a fondo acerca de cómo utilizar con más presión noviolenta hacia la autori- 
dad la fuerza moral y material que la caravana estaba construyendo -como bola de nieve- en las diferentes etapas del camino, y no sólo querer concentrar su acción en el acto final en Ciudad Juárez. Así, se decidió hacer una marcha de toda la caravana desde la plaza de los testimonios hasta la Procuraduría de Nuevo León, muy tarde en la noche casi sin nadie en la calle, y emplazar al Procurador a resolver urgentemente los casos de desaparecidos de ese estado que venían en la caravana y los que habían testimoniado en el templete. A esta acción noviolenta-de una pequeña masa en un espacio abierto- se le agregaba la variable de la fuerza moral de las víctimas, de la hora, de la interpelación firme a la máxima autoridad para que acudiera a media noche, y el lugar: el espacio central del poder frente al delito.

Para reforzar esta acción, se utilizó otra herramienta central de la lucha noviolenta: la firmeza permanente, o sea, no nos retiraríamos de ese espacio sin una solución satisfactoria inmediata, a la hora o día que fuera. Esta "determinación moral y material” fue fundamental para que la autoridad tuviera que aceptar las condiciones del MPJD y la consecuente "exposición pública-mediática” a que fue sometida. El movimiento organizó, por unas horas, una "sentada" (sit-in) afuera de la Procuraduría ante las advertencias atónitas de la población aterrada de Monterrey que no podía creer que hubiera una acción ciudadana a esa hora allí. En un aspecto que no fácilmente se aprecia en el proceso de construir cuerpos para la lucha, esas horas empoderaron, radicalizaron y unieron mucho a los miembros del movimiento (hubo silencios, oraciones y música, diálogos y reflexiones), los dignificaron porque ese es un efecto preciso de "luchar" y entusiasmaron. Además se esbozó un "camino estratégico de acción”, fue un pequeño laboratorio de hacia dónde confrontar al poder para la justicia. En la madrugada salió la comisión del movimiento que participó en la negociación con la autoridad, a informar que se había logrado el objetivo de que en un mes regresaríamos a constatar los avances reales en esos casos de desaparición. Otro elemento estratégico importante de esta acción fue que se logró la articulación entre el movimiento y una ONG local (CADHAC: Ciudadanos en Apoyo a los Derechos Humanos), que era uno de los grandes objetivos de la organización ante la imposibilidad del MPJD de tener presencia propia en todo el país, para el seguimiento de los casos planteados a la Procuraduría.

Con la Caravana del Consuelo, me parece, concluyó esta primera etapa de grandes movilizaciones nacionales -e internacionales- para detener la guerra, donde una "ofensiva estratégica noviolenta"11,desempeñó un papel central. Se activó así positivamente esa reserva moral mexicana hacia el terreno de la lucha social en la calle y existió la denuncia clara hacia la complicidad entre el crimen organizado, las fuerzas del Estado y los sectores económicos; se comenzó a construir una importante herramienta de la noviolencia que es la "fuerza moral" (principalmente de Javier Sicilia y los familiares de las víctimas) que desencadenó a su vez la "fuerza material" (Marín 1995: 26); se visibilizó la magnitud de la guerra en el país con la cifra de al menos 40 mil muertos y 10 mil desaparecidos, así como la dignidad de 
esas víctimas y sus familias que nada tenían que ver con el delito; se desterrorizó por momentos a parte de la población y se posibilitó su unión e inicio de organización; se puso en cuestión el modelo de seguridad pública militarizada como causante central de la espiral de violencia e impunidad; se cuestionó el modelo económico neoliberal como raíz de la pobreza y desamparo que llevan al delito. La sociedad mexicana empezó a tomar conciencia que caminaba sobre un gran piso de sangre, o "una tumba” como dicen hoy los familiares de los 43 desaparecidos en Iguala.

\section{Segunda etapa: diálogo y negociación con los poderes políticos}

La segunda etapa del MPJD, desde el ángulo de la lucha social, se caracterizó por el énfasis del diálogo en la dimensión política y de justicia, buscando cristalizar toda esa movilización ciudadana y fuerza moral en logros concretos sobre los temas centrales de la lucha contra la guerra y la aparición de los desaparecidos. Hubo así tres encuentros públicos: dos con el ejecutivo y uno con el legislativo (28 julio 2011), y cuatro mesas de trabajo con representantes del ejecutivo acerca de los temas centrales a resolver: justicia, “seguridad ciudadana”, violencia en el tejido social y medidas económicas sobre todo para los jóvenes. Esta etapa inició con un hecho inédito en el país (23 de junio de 2011): el presidente Calderón, su esposa y parte de su gabinete, en cadena televisiva nacional, se sentaron a escuchar a un número importante de familiares de familiares de víctimas de todo el país, que presentaron sus testimonios y demandas con enorme claridad, fuerza y dignidad. Además de la parte emotiva, que fue también muy importante para las víctimas y la población nacional, se tomaron acuerdos de tener mesas de trabajo entre las autoridades, las víctimas y miembros del MPJD, en los meses siguientes, lo que duró hasta el segundo encuentro con el presidente.

En paralelo, actores sociales importantes en la dinámica de construcción del movimiento (además de realizar continuamente acciones de protestas simbólicas) se fueron organizando más (medios independientes, artistas, jóvenes, intelectuales, iglesias, movimientos sociales, ONG...) y buscaron ampliar el espectro de las alianzas y la solidaridad nacional e internacional. Se realizaron así pequeñas caravanas y visitas solidarias a comunidades indígenas acosadas por la violencia de todo tipo como Cherán, Ostula, Wirikuta, Acteal, San Cristóbal de las Casas... En cuanto a las alianzas con organizaciones que articulaban a los familiares de las víctimas destacan particularmente los lazos y aprendizajes con las Fuerzas Unidas por Nuestros Desaparecidos en Coahuila (FUNDEC, hoy FUNDEM) y con las Casas del Migrante, encabezadas por el padre Alejandro Solalinde. La visibilización pública de casos de víctimas hizo también necesario iniciar la construcción de una base de datos y sistematización del trabajo con los casos registrados en las caravanas y acciones por voluntarios del movimiento, así como construir acciones para el apoyo psicosocial a los familiares. 
En septiembre (9-19), se organizó y realizó también una segunda “Caravana al sur”, llegando incluso a Guatemala para resaltar la lucha de los migrantes, con el objetivo central de articularnos, escuchar y visibilizar a otro tipo de víctimas -estas centenarias- de la guerra en México, que son las comunidades indígenas y campesinas, que resisten ejemplarmente a la expropiación de sus territorios y a la violencia, a partir de sus organizaciones comunitarias. Pensábamos también que en este último aspecto había muchísimo que aprender acerca de la construcción social y comunitaria de otros modelos de seguridad y reeducación. Entre los múltiples encuentros con organizaciones que hubo en este caminar por el sur, destacó el que se dio en Oventic, por invitación de la Junta de Buen Gobierno del EZLN, en otro gesto solidario del zapatismo con las víctimas del movimiento.

Esta segunda etapa de la lucha, concluyó el 14 de octubre con el Segundo Diálogo Público de los familiares de las víctimas con el ejecutivo, donde los miembros del movimiento que encabezaron las mesas de trabajo -en los dos meses anteriores- declararon el fracaso de ese periodo de trabajo conjunto, ante los logros casi nulos: de 31 casos de violencia presentados sólo se avanzó en la resolución de uno (el del hijo de Javier Sicilia y 6 personas más) y sin que hubieran hasta ese día sentenciados ni apresado a todos los responsables; el modelo de "paz armada" o "seguridad militarizada” permanecía intacto y, al contrario, se potenciaría. Pocos días antes del Diálogo, el gobierno -en un intento de legitimación y simulación- creó apresuradamente una Procuraduría de Atención a Víctimas del Delito (Pro Vícti$\mathrm{ma})$, instancia que atendería casos individuales de violencia, pero sin presupuesto ni personal.

De este segundo Diálogo en el Castillo de Chapultepec, destacó el momento en que algunos familiares de víctimas que acompañaban al movimiento, saliéndose por suerte del protocolo, se pararon frente al presidente para entregarle y explicarle brevemente su expediente de agravios y violencia; destacaron don Nepomuceno Moreno, padre ejemplar de Hermosillo que luchaba por recuperar a su hijo desaparecido, y la autoridad wixárrika Julio de la Cruz que defendía su sitio sagrado de Wirikuta contra una minera canadiense. El presidente les prometió protección y revisar esos casos. Poco más de un mes después, el 28 de noviembre, don Nepo fue asesinado brutalmente al mediodía en pleno centro de Hermosillo.

Una semana antes del diálogo con el presidente Calderón, el 6 de octubre, fue asesinado en su casa Pedro Leiva, autoridad nahua de Santa María de Ostula (Michoacán), quien iba a estar sentado frente al presidente como integrante de las mesas de trabajo. Dos meses después, el 6 de diciembre, en la misma comunidad autónoma nahua de Ostula fue asesinado brutalmente, por la delincuencia organizada, otra importante autoridad y líder social ejemplar, don Trinidad de la Cruz, cuando era acompañado por una pequeña misión de DDHH de 12 personas del MPJD, a solicitud de la comunidad para participar de observadores en una consulta comunitaria para poner fin al conflicto de despojo de tierras que enfrentaban. Ahí se pudo constatar cómo en México, frente al nivel de violencia, contubernio 
delito-gobierno e impunidad existentes, ya no era suficiente la fuerza moral y material de una acción de paz desde la "interposición noviolenta de cuerpos"12.

Esa misma noche del 6 de diciembre del 2011 fue desaparecida en Guerrero otra muy valiosa luchadora social del MPJD y de la Organización de Campesinos Ecologistas de la Sierra de Petatlán y de Coyuca de Catalán (OCESPC) que enfrentaban a los talamontes y el tráfico de droga, poco después de atravesar un retén militar, junto a su compañero de la organización Marcial Bautista.

Hasta hoy no hay ninguna justicia en esos asesinatos directos, ni han aparecido Eva y Marcial.

A raíz del golpe, en todos los sentidos, que recibieron esas familias y organizaciones de activistas sociales y el MPJD, y ante la impunidad total de esa violencia, se replantearon las estrategias de acción noviolenta y de seguridad interna. Se decidió así potenciar un instrumento de la acción directa noviolenta que habían sido las “acciones-espejo”, realizadas para reforzar mesas de trabajo de familiares de las víctimas con autoridades en los estados donde estaban desaparecidos sus hijos, acciones que consistían en una combinación de protestas simbólicas y exigencia pública a las autoridades, en los edificios de las representaciones de los poderes estatales en el DF; se creó así la "Brigada don Nepo”.

\section{Tercera etapa: la imposibilidad de una organización nacional, la ley nacional de víctimas y la multiplicación de organizaciones de víctimas}

Inició así en 2012, una nueva etapa del MPJD que tuvo como uno de sus objetivos -además de seguir avanzando en el tema del Alto a la Guerra y lograr la Aparición de los Desaparecidos- pasar de las movilizaciones a ser un movimiento más organizado, de características nacionales y binacionales, articulado con grupos locales y regionales afines y con los pueblos indígenas, donde se agruparan los familiares de víctimas, se escucharan todas las voces y las decisiones estratégicas y organizativas se asumieran lo más horizontal y colectivamente. Se realizó un importante Encuentro Nacional del movimiento en Cuernavaca, con invitados de la Red Global, el 21 y 22 de abril de 2012, seguido a otro Encuentro Nacional de familiares de víctimas. Diálogo y participación abundaron, acuerdos fueron muchos, pero su cumplimiento y forma de organización interna y con los aliados en las acciones, en la comunicación y la toma de decisiones no pudieron cumplirse en los meses siguientes, lo que aumentó la falta de claridad en su posición política y de relación frente al poder, y los conflictos internos y polémicas dentro del movimiento. Por otra parte, empezaron a ser “observables” fracturas, enfrentamientos sobre estrategias y tácticas, conflictos de liderazgos entre los familiares de las víctimas del MPJD, lo que 
sería el germen de un fuerte debilitamiento, en todo sentido, del movimiento a futuro.

En esos primeros meses del 2012, algunas acciones siempre simbólicas, interesantes -en el campo de la cultura y el arte- de por dónde caminar en la lucha noviolenta fueron la campaña mediática lanzada por un grupo de actores solidarios - parte de esa reserva moral necesaria en la lucha- denominada "En los zapatos del otro", donde se buscaba que la población tomara conciencia de la necesidad de involucrarse en el dolor de tantos seres humanos similares en su identidad social, injusta y brutalmente violentados en su propio país, y también que lo mismo le podía suceder a cualquiera. Igualmente se potenció la construcción de una red nacional de "Bordadores por la paz", que permitía a la gente reflexionar colectivamente, bordar juntas historias de víctimas, para visibilizarlas y denunciar al gobierno. De este modo una considerable porción de la reserva moral mexicana se activaba simbólicamente -al menos- y seguía confrontando públicamente la inhumanidad que padecíamos, se organizaba y rompía el aterrorizamiento social.

En mayo del 2012 se realizó también un Encuentro Público mediático de los familiares de víctimas con los candidatos presidenciales, pues iba a haber elecciones en julio de ese año, con el fin de fijar compromisos de justicia con el próximo gobierno. Con el objetivo de llevar la lucha también fuera de las fronteras del país, donde estaban muchas de las causas de la violencia de nuestra guerra (consumo de drogas, tráfico de armas, lavado de dinero, ataques a migrantes...) se realizó una "Caravana Binacional a Estados Unidos”. Duró del 12 de agosto al 12 de septiembre de 2012, con más de 80 organizaciones de Estados Unidos involucradas en la organización de actos diarios de testimonio de víctimas de la "guerra a las drogas", las políticas migratorias de México y EU, y el despojo trasnacional de los recursos naturales, recorriendo del oeste al este, y del sur al norte del país, iniciando en san Diego y terminando en Washington. Hubo en esta Caravana acciones noviolentas simbólicas emblemáticas y mediáticas, encabezadas por Javier Sicilia y las víctimas individuales y colectivas que viajaron.

El 18 de enero de 2013 se cumplió uno de los mayores objetivos de lucha de las víctimas del MPJD y de su líder Javier Sicilia: fue aprobada la Ley General de Víctimas, después de muchos meses de acciones políticas y noviolentas de presión de todo tipo, la cual según opiniones de especialistas es una de las más avanzadas del mundo. Prevé un Sistema y un Registro Nacional de Víctimas, un Fondo de Ayuda, Asistencia y Reparación a Víctimas, y muchos aspectos positivos más. Se creó también, tiempo después, la Comisión Ejecutiva de Atención a Víctimas (CEAV), cuyos miembros (7) menos uno fueron designados por el poder político, en una clara demostración de la poca fuerza que ya tenían el MPJD, las ONGs aliadas y las organizaciones de víctimas en ese momento. Hasta hoy la operación real de la Ley -sin un Reglamento todavía-, de la CEAV, en el nivel nacional y estatal, ha sido fuertemente cuestionada -una desilusión y simulación total- en todo sentido, en una típica acción política del “gatopardismo” mexicano. 
En el mismo mes de 2013 hubo también un $2^{\circ}$ Encuentro Nacional del MPJD en el DF, con presencia de representantes de organizaciones de EU y Canadá, en un nuevo intento por articular formas organizativas, de toma de decisiones y de estrategias de lucha entre diversos grupos y movimientos del país, pero nuevamente falló este intento por muy diversas razones: la dinámica de la conflictividad social y represión en el país; la presión de violencia de muchas organizaciones en sus localidades con características muy particulares; las políticas económicas del nuevo gobierno y su autoritarismo político; las políticas de cooptación y engaño -nacional e internacional- del nuevo gobierno; la identidad social, organizativa, de lucha y de toma de decisiones de los grupos; los diferentes estilos y formas de lucha de las víctimas individuales y colectivas del movimiento; los ritmos del proceso de empoderamiento y liderazgo social de los familiares de víctimas dentro del MPJD y de otros movimientos similares aliados; el estilo de liderazgo de algunos activistas sociales.

En el transcurso del 2013, consideramos, el MPJD cambió fuertemente su identidad, su capacidad de presión política, social y mediática, su cohesión interna, sea entre activistas que entre familiares de víctimas. Se ahondó una crisis de identidad, incluso en las formas de construir la "memoria colectiva” de esta guerra; de consenso acerca de la estrategia y tácticas de la lucha social y política así como del diagnóstico de la realidad nacional; de relaciones humanas internas fraternales y solidarias; de formas de liderazgo en los activistas sociales, en Javier Sicilia y su entorno de confianza, y en los familiares de las víctimas. A partir de una fragmentación de los liderazgos de víctimas del MPJD, y del crecimiento de la lucha de familiares y la guerra en todo el país, se dio un aumento muy importante en el número de organizaciones de víctimas en todos los estados del país, y también en su experiencia acumulada en esos primeros años acerca de las mejores formas de presionar al poder político para lograr verdad, justicia, reparación y memoria.

\section{Formas de lucha noviolenta: una reflexión final}

¿Qué esbozos de reflexión podemos adelantar a partir de esta experiencia tan reciente, y aún viva, de lucha social que sea útil a otros y otras que luchan, por las causas legítimas que sean?

Respecto a las formas de acción del MPJD, sobre todo en sus primeros dos años de 2011 al 2013, ciertamente se hicieron muchas movilizaciones de masas (caravanas, marchas...), hubo también un diálogo directo con los poderes -que tuvo más de simulación e impunidad que de logros-. La reserva moral movilizada (en cuanto a individualidades, actores sociales organizativos y comunitarios claves, como el zapatismo, por ejemplo), el liderazgo moral de Javier Sicilia y los familiares de víctimas con sus testimonios valientes y directos contra el contubernio gobierno-delito, el tener la "verdad” y el gran apoyo mediático nacional e internacional, fueron importantes "armas noviolentas" que, en cierto sentido, compensaron la falta de 
mayor intensidad y radicalidad -en el enfoque de la "firmeza permanente"en las acciones noviolentas instrumentadas en relación al nivel de violencia e impunidad que se enfrentaba. Pero, a la larga esto no fue suficiente, pues no se logró pasar a la etapa que la historia de la resistencia civil noviolenta enseña: la no-cooperación y la desobediencia civil. Cuando hay un nivel tan grande de violencia, impunidad y complicidad del Estado, si no se activan otras escalas de mayor radicalidad moral y material en las acciones, la presión de las movilizaciones de masas y el diálogo ante las autoridades no son suficientes, porque se permite que el Estado tenga márgenes de simulación, de "gatopardismo”, y de crear “instituciones virtuales”-como la Ley de Víctimas y Províctima- que en la práctica no operan para lo que fueron realmente creadas. Como diría el Dr. Marín, “se impuso el empirismo lógico del poder, al hacernos creer que el discurso es la realidad”.

El poder político logró llevar la lucha social, y la gran confrontación a su legitimidad y legalidad que el MPJD le creó en su primera etapa, hacia el terreno -espacio social- que domina: lo institucional, lo jurídico, la negociación política, la cooptación, la “penetración”, la amenaza y el miedo. Lo hizo bajo muchas, muy variadas y sutiles a veces tácticas, pero logró “desprocesar” el nivel de confrontación directa noviolenta y moral que el MPJD y otros movimientos similares le plantearon inicialmente.

Así, en la resistencia civil noviolenta mexicana, la escala de denuncia-diálogo-foro-negociación-movilización de masas se ha demostrado insuficiente para presionar al Estado en lograr avances en la aparición de los desaparecidos, en la justicia para los muertos y en el cambio del modelo de seguridad militarizada, guerra y despojo económico. No es suficiente sólo el carácter masivo de una acción para otorgarle la intensidad de presión que hay que ejercer ante la autoridad. Aunque sí han habido algunas acciones de mayor radicalidad, pero no continuadas estratégicamente por más personas ni acompañadas por el movimiento en su conjunto: dos huelgas de hambre de familiares de víctimas frente a la Secretaría de Gobernación; la organización de búsqueda de desaparecidos directamente por familiares (Baja California, Guerrero, Morelos, Coahuila, Chihuahua), algo que afortunadamente ya es una decisión tomada por muchas organizaciones de víctimas, que muchos se debatió sin éxito dentro del MPJD, y que marca el camino de la imprescindible autonomía frente al poder $\mathrm{y}$, consecuente, empoderamiento de las víctimas como actores directos de su búsqueda de la verdad y justicia.

Uno de los mayores “obstáculos epistémicos” en la lucha noviolenta es hasta dónde apostar por el "cambio del adversario”, y en esta relación de confrontación con el "otro” cuáles son los “valores noviolentos” y de "humanización del adversario” que se buscan, es un tema muy reiterado y complejo en el que no ahondaré ahora. Pero sí mencionaré que en el MPJD fue determinante en las diferentes concepciones y enfoques de la noviolencia que se enfrentaron, en mucho desde el liderazgo de Javier Sicilia que apostó siempre al cambio positivo de las autoridades, a través de una relación y gestos lo más cordiales posibles aunque sí con una denuncia 
clara. Creo que no es correcto plantear la identidad social de alguien como un "todo individual" sino como un gran "entramado social" -como diría Norbert Elías-, por lo que sus decisiones no dependen sólo de él, más bien en mayor medida dependen de las relaciones sociales que lo "pusieron en ese lugar”.

Este aspecto tiene que ver también en la construcción del conflicto social con el adversario, donde varios miembros del MPJD -incluso líderesno tenían mucha experiencia previa de lucha social directa contra el poder. En particular la mayoría de los familiares de víctimas eran parte de una clase social media o pobre que, al contrario, “creía en sus autoridades” y las “obedecía ciegamente”, por lo que su proceso de "ruptura epistémica” y posteriormente moral, se prolongó bastante ya que implicaba negar muchos valores determinantes en su construcción humana pasada. Ese proceso de fuerte lucha social, de las víctimas de la guerra y el MPJD, originó un cambio de identidad social en muchas personas mexicanas: pasando de la apatía o indiferencia a la solidaridad, y de la solidaridad a la lucha. Estos cambios son muy complejos, tardados y dolorosos, nada “mecánicos” ni fáciles de lograr.

Por otro lado, en lo estratégico, también es cierto que el MPJD no se logró articular con los pueblos indios y el Ejército Zapatista de Liberación Nacional (EZLN). Los pueblos indios y el EZLN fueron muy generosos en su ofrecimiento de articulación con las víctimas, en sus movilizaciones solidarias, pero hubo complicaciones de entendimiento y pre-juicios. Hay que asumir que existieron, por lo menos, dificultades culturales y de experiencia política y de lucha, de estilos de liderazgos, para entender la dinámica de los pueblos indios, y se perdió la gran oportunidad de crear realmente un movimiento nacional de masas organizadas de víctimas y sociedad civil solidaria organizada, con toma de conciencia como sujetos sociales, junto a los pueblos indios, que son los que por lejos tienen en el país las formas de luchas más claras y avanzadas de resistencia civil y seguridad. Ellos son los que mejor conocen y actúan el modelo hacia dónde caminar en defensa de los territorios y la seguridad, de una economía solidaria, autosuficiente, integrada regionalmente, autónoma, de educación y salud en manos del pueblo.

Un aspecto ético-moral muy importante para el MPJD son los asesinatos y desapariciones directas hacia activistas sociales que se tuvieron. Todos y todas ellos y ellas fueron seres humanos absolutamente ejemplares para la historia de México, siempre dieron todo lo que tenían e impulsaban a todos y todas a caminar hacia adelante en la lucha por la justicia. En ninguno de estos casos hay verdad, justicia, reparación ni memoria al día de hoy.

Por todo ello, en México antes que hablar de paz y memoria hay que hablar de verdad y justicia. 


\section{Notas}

${ }^{1}$ Este concepto asociado a los conflictos sociales se lo debemos al Dr. Juan Carlos Marín, notable sociólogo y epistemólogo argentino indispensable para el conocimiento y la investigación de los procesos sociales. Está retomado, en parte, de Freud.

${ }^{2}$ Tomo este periodo porque es en el que el MPJD estuvo más claramente identificado pública e internamente como una organización con identidad y acción propia; con acciones noviolentas públicas de considerable intensidad; además es el periodo en el que personalmente estuve directamente involucrado en el movimiento con más intensidad y responsabilidad.

${ }^{3}$ En el último Informe (enero 2016) Un trato indolente. La respuesta del Estado frente a la desaparición de personas en México de Amnistía Internacional, se señala que "en México existe una epidemia de desapariciones" debida a la "incompetencia, inercia e indolencia del gobierno". Y se agrega que, según cifras oficiales, casi la mutad de los 27600 desaparecidos o no localizados se registraron durante la administración del presidente Peña Nieto (3425 en 2015).

${ }^{4}$ Esto quedó ampliamente probado con el Informe del Grupo Interdisciplinario de Expertos Independientes (GIEI) de la Comisión Interamericana de Derechos Humanos (CIDH), entregado a la opinión pública el 6 de septiembre de 2015, donde se demuestra que el C4 (máximo organismo nacional de Inteligencia y Coordinación Policial) del país estuvo al tanto de todo lo que estaba sucediendo en Iguala minuto a minuto, y no intervino para detener nada de esa violencia genocida.

${ }^{5}$ Tomamos este concepto de "reserva moral” y su contenido del Dr. Juan C. Marín. En (Wallerstein 2010) se le llama "hegemonía moral”.

${ }^{6}$ A influencia de Marín, la Declaración Final del XXII Congreso de la Asociación Latinoamericana de Sociología (ALAS), en Concepción, Chile (octubre de 1999, asentó: "Postulamos así la urgencia de colaborar en la construcción de un juicio moral que haga posible la ruptura con las formas de obediencia acrítica a la autoridad, haciendo observable y promoviendo la desobediencia debida a toda orden de inhumanidad”.

${ }^{7}$ Esta "relación de escala" entre nuestras acciones y las del adversario, tomando claramente en cuenta una multiplicidad y complejidad de factores, es una de las medidas más importantes de nuestra radicalidad moral y estrategia de la lucha social. Constituye uno de los principales "inobservados" en el grado de la determinación de las partes en lucha.

${ }^{8}$ Frase que hizo famosa el Comandante zapatista David en Oventic el 7 de agosto de 2003 al proclamar la creación de las Juntas de Buen Gobierno: “Autonomía sin pedir permiso".

${ }^{9}$ Gandhi comparaba el estado de la noviolencia en su tiempo con el de la electricidad en la época de Thomas Edison.

${ }^{10}$ El silencio (que los zapatistas tan bien han usado en su lucha) y la poesía fueron dos importantes "armas noviolentas" en la lucha del movimiento. El EZLN, en una muestra de gran apoyo, se adhirió a la "Marcha silenciosa por la Paz" al DF, con su mayor 
Polis, Revista Latinoamericana, Volumen 15, $N^{\circ}$ 43, 2016

movilización en años recientes, de 35 mil zapatistas que marcharon silenciosamente en San Cristóbal de las Casas el 7 de mayo de 2011.

${ }^{11}$ Gandhi, en cierto sentido, llamaba a este aspecto "tener la iniciativa”.

${ }^{12}$ El 27 de abril del año anterior ya se había registrado un muy doloroso, y peligroso, antecedente al respecto cuando fueron brutalmente asesinados por paramilitares triquisBeti Cariño y JyriJaakkola -voluntario finlandés- cuando participaban en una Caravana de Ayuda Humanitaria al municipio triqui autónomo de San Juan Copala cercado militarmente. 


\section{Bibliografía}

Ameglio, P. (2013), “Caminar y luchar: acción y espiritualidad noviolentas,” en Iglesias por la paz. Espiritualidad en las caravanas del MPJD, Centro de Estudios Ecuménicos, pp. 22-32, México.

Ídem (2011),“La reserva moral mexicana sale a la calle”, en Proceso, 17 abril, México.

Ídem (2014), “A tres años del MPJD: es necesario hablar más de justicia y menos de paz”, en Cristus, noviembre, México.

Ídem (2012), “El Movimiento por la paz y su lucha noviolenta”, en Brújula Ciudadana, junio, México.

Barbé, D. et al. (1977), A Firmeza-Permanente. A Forca da Nao-Violencia. Coedición Loyola-Vega, Sao Paulo.

Colectivo “Angela Esperanza” (2014), El estado de la guerra en México hoy. En: http://webiigg.sociales.uba.ar//revistacuadernosdemarte/revista.htm, n. 6 .

Ídem (2013), El ‘exterminio selectivo’en México hoy, Mimeo, México.

Díaz De Los Reyes, K. (2014), "Yo soy \#132, una forma de resistencia por la paz”, en Ameglio, P. y T. Ramírez (coords.).Antología. ¿Cómo construir la paz en el México actual? Textos, autores y preguntas sobre cultura y educación para la paz. México, Universidad de El Claustro de Sor Juana, Edit. Plaza y Valdés, UAEM, SERPAJ, en imprenta, México.

Equipo Bourbaki (2011), El costo humano de la guerra por la construcción del monopolio del narcotráfico en México (2008-2009), en http:// webiigg.sociales.uba.ar//revistacuadernosdemarte/revista.htm, n.1

Gil-Olmos, J. (2013), “Sólo el pueblo puede defender al pueblo”, en Proceso, 24 noviembre, México.

Grupo Interdisciplinario de Expertos Independientes (GIEI) (2015), Primer Informe de Avances, México.

Marín, J.C. (1995), Conversaciones sobre el poder. Universidad de Buenos Aires, Instituto “Gino Germani”, Buenos Aires.

Ídem (2007), Los hechos armados. Argentina 1973-1976. La acumulación primitiva del genocidio. Ed. La Rosa Blindada, P.I.CA.SO., Buenos Aires.

Ídem (2014), “Conocimiento y desobediencia debida a toda orden inhumana”. Prólogo de M. Fracchia. UAEM, México 
Olivares A., E. (2015), “Persiste una grave crisis de derechos humanos y el gobierno lo niega: ONG”, en La Jornada, 6 de octubre, p. 3, México.

Piaget, J. (1985), El criterio moral en el niño. Roca Edics. México

Román, J.A. (2015), “Dejaron su lugar de origen por violencia 6\% de los mexicanos”, en La Jornada, 21 de diciembre, p.8, México.

Ídem (2016), “Padece México epidemia de desapariciones, asegura AI”, en La Jornada.,15 enero, p.3, México.

Tejera, A. (2011), “Desapariciones forzadas en México, al nivel de las dictaduras de América Latina: Amnistía Internacional”, en La Jornada, 2 agosto, p.5, México.

Wallerstein, I. (2010), “Marcos, Mandela y Gandhi”, en La Jornada, México, 9 octubre, México.

Recibido: 30.01.2016

Aceptado: 05.04.2016 